\title{
SILICA SUPPORTED THALLIUM (III) NITRATE: AN EFFECTIVE OXIDANT FOR OXIDATION OF ALCOHOLS TO THE CARBONYL COMPOUNDS
}

\author{
ABBAS AMINI MANESH* AND TAHEREH NAZARI \\ "Department of Chemistry, Payame Noor University, 19395-4697 Tehran, I. R. of IRAN.
}

\begin{abstract}
Thallium (III) Nitrate Supported on Silica gel was found to be an efficient reagent system for oxidation of primary and secondary alcohols to their corresponding carbonyl compounds under mild conditions. The striking features of our method are: short reaction times, formation of no over oxidation products due to high selectivity and mild nature of oxidant, easy work-up procedure, high yields and carbon carbon double or triple bond functional group in the alcohol structure does not oxidize to other group.
\end{abstract}

Key words: Oxidation, Thallium (III) Nitrate, Alcohols, Silica gel.

\section{INTRODUCTION}

The oxidation of alcohols to the corresponding carbonyl compounds is one of the most fundamental and important transformations in synthetic organic chemistry. In particular, selective cascade oxidative transformations of alcohols to carbonyl compounds (i.e., primary alcohols $\rightarrow$ aldehydes $\rightarrow$ carboxylic acids; secondary alcohols $\rightarrow$ ketones $\rightarrow$ esters; cycloalkanols $\rightarrow$ cycloalkanones $\rightarrow$ lactones or cyclic $\alpha, \beta$ - enones, etc.) are attractive, since the target molecule can be obtained directly in one-pot sequences. To date, many excellent catalytic methods have been developed for alcohol oxidations .$^{1-6}$ The concept of using reagent adsorbed on inert inorganic supported has been applied in organic synthesis. There is current research and general interest in heterogeneous systems because of the importance such systems have in industry and in developing technologies . ${ }^{7}$ Such efficiency resulting from inorganic material- supported reagent may come from the combination of three factors: (i) an increase in the effective surface area for reaction; (ii) the presence of pores which constrain both substrate and catalyst and thus lowers the activation entropy of reaction;(iii) the acceleration of the reaction resulting from bringing substrate and reagent into proximity ${ }^{8}$ These novel reagents have advantages over the conventional homogeneous solution techniques, such as: easy set- up and work-up, mild experimental condition, and high yield and selectivity $9^{9-10}$

During the course of our systematic study on oxidation of organic compounds,${ }^{11-17}$ we report herein an oxidation of alcohols to the carbonyl compounds with Thallium (Ш) Nitrate (TTN) supported on Silica gel catalyzed by $\mathrm{AlCl}_{3}$ in solution, scheme 1 .

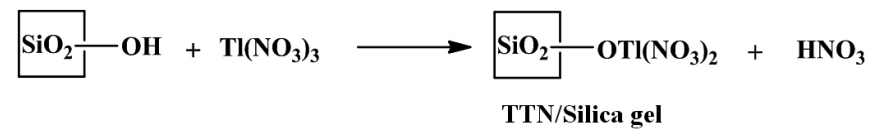

Scheme 1

Since transition metal cations are highly toxic and carcinogenic species, its application with any dispersion is very interesting for organic and biochemists. In this article, a new procedure with clean work-up and easy removal of chemical waste (due to the heterogeneous nature) was described. Different types of alcohols (primary and Secondary) were subjected to the oxidation by thallium (III) nitrate supported on Silica gel (TTN/Silica gel) in the presence of $\mathrm{AlCl}_{3}$. The overall reaction is best formulated in the scheme 2 .<smiles>[R]C(O)C1CC2(O[Na])CCC1(O[Na])CC2</smiles><smiles>[R]C([R])=O</smiles>

The oxidation reactions were performed under mild and completely heterogeneous conditions with good yields, (Table 1).

\section{RESULTS AND DISCUSSION}

The XRD profiles of the samples at $298^{\circ} \mathrm{K}$ are shown in Figure 1 and 2. Powder X-ray diffraction (XRD) patterns were recorded on a Philips PW-1840 $\mathrm{X}$-ray diffractometer (XRD) with $\mathrm{Cu} \mathrm{K} \alpha$ radiation. The intensity data were collected over a $2 \theta$ range of $10-90^{\circ}$. Comparison of the 2 XRD spectra showed that $\mathrm{Tl}\left(\mathrm{NO}_{3}\right)_{3}$ particles were supported on silica gel ( any increase in width of crystal sheets of materials cause decrease in peak width of XRD spectra).$^{18-19}$

The XRD results revealed the presence of $\mathrm{Tl}\left(\mathrm{NO}_{3}\right)_{3}$ over the amorphous $\mathrm{SiO}_{2}$ matrix in the case of $\mathrm{Tl}\left(\mathrm{NO}_{3}\right)_{3}-\mathrm{SiO}_{2}$ (see $2 \theta=10-60^{\circ}$ ), and some overlapped regions. The particles sizes of the $\mathrm{Tl}\left(\mathrm{NO}_{3}\right)_{3}$ on $\mathrm{SiO}_{2}$ according to scherrer equation was estimated as $90 \mathrm{~nm}$ (figure 2).

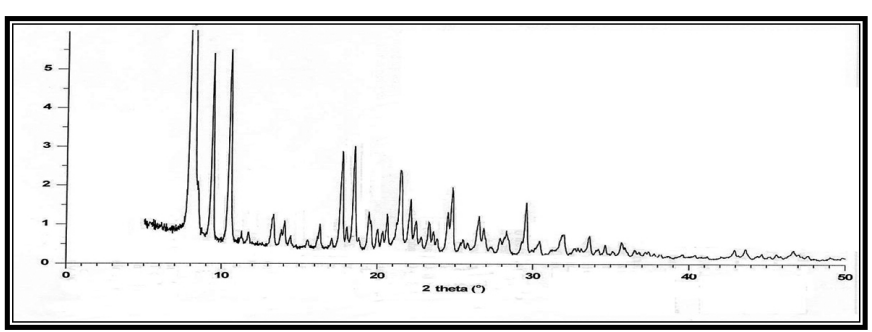

Figure 1: XRD spectrum of $\mathrm{SiO}_{2}$

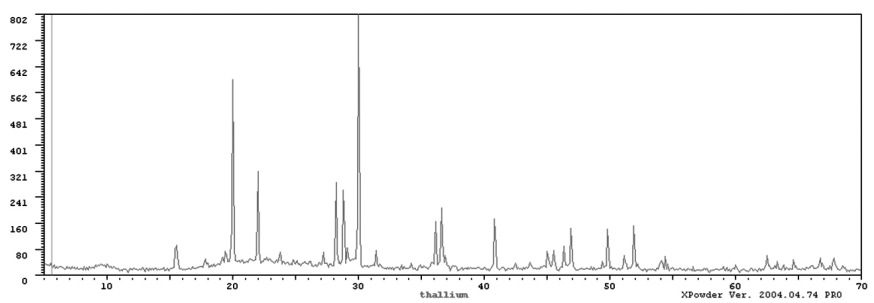

Figure 2: XRD spectrum of TTN supported on $\mathrm{SiO}_{2}$

The results of the conversions of various alcohols to their corresponding carbonyl compounds are presented in Table $\mathbf{1}$. 
Table 1: Oxidation of primary and secondary alcohols using $\mathrm{TTN} / \mathrm{SiO}_{2}$ in the presence of $\mathrm{AlCl}_{3}$

\begin{tabular}{|c|c|c|c|c|}
\hline Entry & Substrate & Product & Time(min) & Yield $(\%)^{a, b, c}$ \\
\hline 1 & & & 35 & 75 \\
\hline 2 & & & 25 & 56 \\
\hline 3 & & & 60 & 67 \\
\hline 4 & & & 35 & 80 \\
\hline 5 & & & 90 & 63 \\
\hline 6 & & & 45 & 67 \\
\hline 7 & $\mathrm{CH}_{3}$ & & 25 & 78 \\
\hline 8 & & & 45 & 73 \\
\hline 9 & & & 60 & 65 \\
\hline 10 & $\mathrm{CH}_{3}\left(\mathrm{CH}_{2}\right)_{6} \mathrm{CH}_{2} \mathrm{OH}$ & $\mathrm{CH}_{3}\left(\mathrm{CH}_{2}\right)_{6} \mathrm{CHO}$ & 60 & 43 \\
\hline 11 & $\mathrm{CH}_{3} \mathrm{CHOHCH}_{2} \mathrm{CH}_{2} \mathrm{CH}_{3}$ & $\mathrm{CH}_{3} \mathrm{COCH}_{2} \mathrm{CH}_{2} \mathrm{CH}_{3}$ & 90 & 53 \\
\hline 12 & $\mathrm{CH}_{3}\left(\mathrm{CH}_{2}\right)_{2} \mathrm{CH}_{2} \mathrm{OH}$ & $\mathrm{CH}_{3}\left(\mathrm{CH}_{2}\right)_{2} \mathrm{CHO}$ & 60 & 73 \\
\hline
\end{tabular}

a Products were characterized by their physical costants, comparison with authentic samples and melting points of 2,4-dinitro phenyl hydrazone derivatives ${ }^{20-24}$ and IR and NMR spectra; ${ }^{b}$ Isolated yields ; ${ }^{\mathrm{c}}$ Reaction Condition: alcohol (1 mmol), DMSO, $\mathrm{CH}_{3} \mathrm{CN}$, TTN/Silica gel(1 mmol), $\mathrm{AlCl} \mathrm{l}_{3}$ under reflux.

As shown in Table 1, not only sterically demanding secondary alcohols (entries $3,6,7$ ), but also unsaturated alcohols (entries $2,4,5,9$ ) were oxidized to the corresponding $\alpha, \beta$-unsatureted carbonyl compounds without the cleavage of carbon-carbon double bond, scheme 3 .

It is difficult to oxidize primary alcohols selectively to the corresponding aldehydes, but in this method, we oxidized primary alcohols to the aldehydes and no acid was formed due to over oxidation of the regenerated aldehydes (entries 1, 2, 4, 5, 9, 10 and 12), scheme 4.

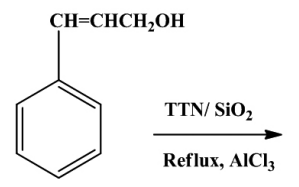<smiles>C=Cc1ccccc1</smiles>

\section{Oxidized $\mathrm{C}=\mathrm{C}$ bond of alcohol}

$63 \%$
Scheme 3: Selective oxidation of unsaturated alcohol<smiles>OCc1ccccc1</smiles>

$\mathrm{TTN} / \mathrm{SiO}_{2}$

Reflux, $\mathrm{AlCl}_{3}$<smiles>O=Cc1ccccc1</smiles><smiles>O=C(O)c1ccccc1</smiles>

Scheme 4: Selective oxidation of benzyl alcohol

In order to establish the catalytic activity of our oxidant (TTN/Silica gel), we compared our results on the oxidation of diphenyl methanol (as a typical example) with data from the literature (Table 2). As shown in Table 2, the previously reported procedures suffer from one or more disadvantages such as elevated reaction temperatures, longer reaction times, and special efforts for the preparation of catalyst. 
Table 2: Comparison of the different methods used for the oxidation of diphenyl methanol

\begin{tabular}{|c|c|c|c|c|}
\hline Entry & Reagent & Time (min) & Yield $(\%)^{\mathrm{a}}$ & Reference \\
\hline 1 & aqueous solution of TBAOX catalyzed by $\mathrm{CuPc}$ & 30 & 80 & 25 \\
\hline 2 & Oxone (2.4 equiv.), $\mathrm{AlCl}_{3}$ (2.7 equiv.) & 240 & 98 & 26 \\
\hline 3 & $\mathrm{~V}_{2} \mathrm{O}_{5}(0.05 \mathrm{mmol})$ aq TBHP $(70 \%, 4 \mathrm{mmol})$ & 480 & 99 & 27 \\
\hline 4 & $\begin{array}{c}{\left[\mathrm{Co}(\mathrm{L})_{2}\right]\left(\mathrm{NO}_{3}\right)_{3} .2 \mathrm{CH}_{3} \mathrm{OH}(0.05 \mathrm{mmol}),} \\
\mathrm{H}_{2} \mathrm{O}_{2}(3 \mathrm{mmol})\end{array}$ & 480 & 36 & 28 \\
\hline 5 & $\begin{array}{c}\text { silica based cobalt (II) interphase } \\
\text { catalyst }(0.25 \% \mathrm{~mol}), \text { NHPI }(1 \mathrm{mmol}), \mathrm{O}_{2}\end{array}$ & 3300 & 94 & 5 \\
\hline 6 & $\begin{array}{l}\text { TTN/Silica gel }(0.834 \mathrm{~g}, 1 \mathrm{mmol} \text { TTN }) \\
\mathrm{AlCl}_{3}(0.75 \mathrm{mmol})\end{array}$ & 60 & 67 & This method \\
\hline
\end{tabular}

${ }^{a}$ Isolated Yield.

This procedure offers several major advantages: (1) the use of a commercially available, cheap, and chemically stable reagent and oxidant; (2) highly efficient for the selective oxidation of structurally diverse alcohols in good yields; (3) control over the degree of oxidation offers access to aldehydes (and not to acids); (4) excellent chemoselectivity. We believe the present method to be an improvement with respect to other procedures.
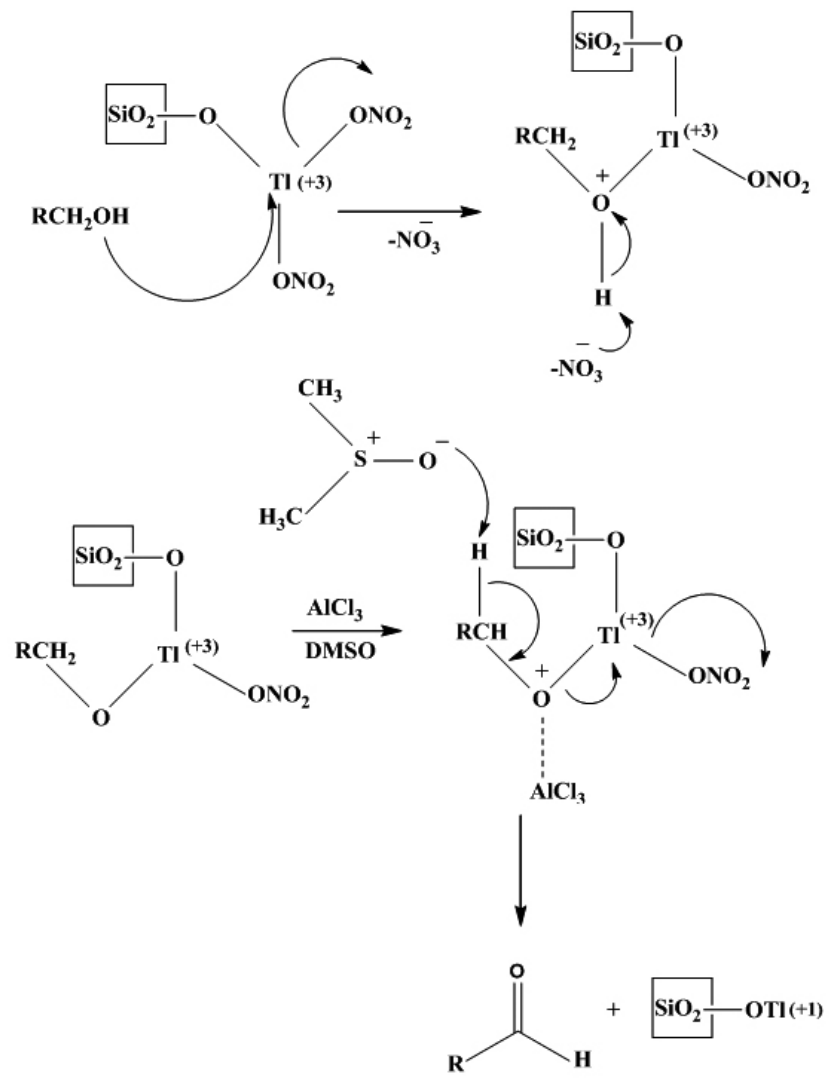

\footnotetext{
$\underset{\left(\mathrm{CH}_{3}\right)_{2} \mathrm{~S}-\mathrm{OH}}{\stackrel{+}{-}-\mathrm{NO}_{3} \longrightarrow} \longrightarrow\left(\mathrm{CH}_{3}\right)_{2} \mathrm{~S}=\mathrm{O}+\mathrm{HNO}_{3}$
}

Scheme 5 shows the proposed mechanism for this oxidation.

\section{CONCLUSION}

In this article we would like to report a simple and convenient method for the effective conversion of alcohols to their corresponding aldehydes or ketones under heterogeneous conditions. The striking features of our method are: short reaction times, formation of no over oxidation products due to high selectivity and mild nature of oxidant, easy work-up procedure, high yields and carbon carbon double or triple bond functional group in the alcohol structure does not oxidize to other functional group.

\section{EXPERIMENTAL}

\section{General Remarks}

Chemicals such as alcohols, Thallium (III) nitrate, $\mathrm{AlCl}_{3}$, DMSO, acetonitrile and silica gel were purchased from Fluka, Merck and Aldrich chemical companies. The oxidation products were characterized by comparison of their Spectra (IR, ${ }^{1} \mathrm{H}$ NMR), TLC and physical data with the authentic samples.

\section{Preparation of the TTN/Silica gel reagent}

Thallium nitrate (TTN. $\left.3 \mathrm{H}_{2} \mathrm{O}\right)(20 \mathrm{~g}, 45 \mathrm{mmol})$ was dissolved in acetone $(60 \mathrm{~mL})$ and Silica gel $(20 \mathrm{~g})$ was then added under stirring at $25^{\circ} \mathrm{C}$ for 45 $\mathrm{min}$. The excess solvent was evaporated under reduced pressure using a rotary evaporator. The white powder solid was dried in vacuum desiccators. TTN/ Silica gel can be stored for at least 2 months in air and at room temperature without losing its activity. ( $1 \mathrm{~g}$ TTN/Silica gel contains $0.468 \mathrm{~g}$ TTN or 1.19 mmol TTN).

\section{General procedure for oxidation of alcohols in solution}

In a round-bottomed flask $(25 \mathrm{~mL})$ equipped with a magnetic stirrer and condenser, a solution of alcohols $(1 \mathrm{mmol})$ and DMSO $(0.2 \mathrm{~mol} \%)$ in $\mathrm{CH}_{3} \mathrm{CN}$ $(5 \mathrm{~mL})$ was prepared. TTN/Silica gel $(0.834 \mathrm{~g}$ which contain $1 \mathrm{mmol}$ TTN $)$ and $\mathrm{AlCl}_{3}(0.75 \mathrm{mmol})$ was added to the solution and the mixture was refluxed for the appropriate times as indicated in Table 1 .

The progress of the reaction was followed by TLC $\left(\mathrm{CCl}_{4} / \mathrm{EtOAC}: 4 / 1\right)$. After completion, the reaction mixture was filtrate and the solid material was washed with $\mathrm{CH}_{3} \mathrm{CN}(10 \mathrm{~mL})$. The filtrate was evaporated and the resulting crude material was purified by column chromatography on silica gel to afford the pure product.

Products were characterized by their physical constants, comparison with authentic samples and IR and NMR spectra. ${ }^{20-24}$

\section{ACKNOWLEDGEMENTS}

The authors acknowledge to Hamedan Payame Noor University Research Councils for support of this work.

\section{REFERENCES}

1. B.M. Trost, I. Fleming, S.V. Ley, Comprehensive Organic Synthesis: Oxidation, Pergamon Pr, (1991).

2. G. Tojo, M. Fernandez, Oxidation of Alcohols to Aldehydes and Ketones; Springer; Berlin, (2006).

3. C. Y. Lorber, J. A. Osborn, Tetrahedron Lett., 37, 853 (1996).

4. H. Hosseini-Monfared, C. Nather, H. Winkler, C. Janiak, Inorganica Chimica Acta 391, 75, (2012).

5. F. Rajabi, B. Karimi, J. Mol. Catal. A: Chem. 232, 95 (2005).

6. R. A. Sheldon, I. W. C. E. Arends, A. Dijkman, Catal. Today, 57, 157 (2000). 
7. E. D. Taylor, C. S. Chiang, A. McKillop, J. F. White, J. Am. Chem. Soc., 98(21), 6750 (1976).

8. K. Burgess, Solid- Phase Organic Synthesis, 1 th ed.; Wiley- Interscience, (1999).

9. N. Noroozi-Pesyan, A. H. Dabbagh, Molecules, 10, 1364 (2005).

10. A. Mckillop, D.W. Young, Synthesis, 481 (1979).

11. A. Khazaei, A. Amini Manesh and A. Rostami, J. Chem. Res., 6, 391 (2005).

12. A. Khazaei, A. Amini Manesh, J. Braz. Chem. Soc., 16 (4), 874 (2005).

13. A. Khazaei, A. Amini Manesh, A. Rostami, J. Chem. Res., 10, 695 (2004).

14. A. Khazaei, A. Amini Manesh, A. Rostami, Phosphorus, Sulfur Silicon Relat. Elem., 179 (12), 2483 (2004).

15. A. Khazaei, A. Amini Manesh, Synthesis- Stuttgart, 12, 1929 (2005).

16. A. Khazaei, A. Amini Manesh, J. Chin. Chem. Soc., 52 (5), 1017 (2005).

17. A. Khazaei, A. A. Manesh, Mendeleev Commun., 16 (2), 109 (2006).

18. H. Freiser, Concepts and Calculations in Analytical Chemistry, CRC, Florida, (1992).
19. D. A. Skoog, D. M. West, Principles of Instrumental Analysis, HoltSaunders, Tokyo, (1987).

20. Vogel's Textbook of practical organic chemistry, fourth edition, (1986).

21. G. Sarifuddin, A. Rajakumar, RSC. Adv. 2, 7781 (2012).

22. S. K. M. Islam, S. Paul, A. S. Roy, P. Mondal, J. Inorg. Organomet. Polym., 23(3), 560 (2013).

23. C. J. Pouchert, The Alderich Library of Infrared Spectra, Edition 3, Alderich Chemical Company, Inc. (1981).

24. C. J. Pouchert, The Alderich Library of NMR Spectra, Edition 2, Alderich Chemical Company, Inc. Vol. 1, (1983).

25. A. Rezaeifard, M. Jafarpour, A. Naeimi, M. Salimi, Inorg. Chem. Commun., 15, 230 (2012).

26. S. Wu, H. Ma, Z. Lei, Tetrahedron, 66, 8641 (2010).

27- K. Alagiri, K. Ramaiah Prabhu, Tetrahedron, 67, 8544 (2011).

28- A. Nemati Kharat, A. Bakhoda, B. Tamaddoni Jahromi, Polyhedron, 30, 2768 (2011). 